\title{
Diagnostic imaging algorithm for cervical soft disc herniation
}

\author{
Erik Van de Kelft, Michel van Vyve
}

\begin{abstract}
MRI with surface coils is currently the preferred method for evaluating degenerative cervical spine disease. The differentiation between soft disc herniation and osteophytic spurs is not always obvious, however, on a 0.5 Tesla unit. The procedure of choice for soft disc herniation, MRI on a $0.5 \mathrm{~T}$ superconducting system associated with plain radiography of the cervical spine, in selecting patients for anterior cervical discectomy without interbody fusion (ACD), was evaluated. This prospective study comprised 100 patients with cervical radicular symptoms, not subsiding after conservative treatment. Plain radiographs were obtained for all patients. Patients without spinal instability, spondylosis, or major osteophytes on plain radiographs and without clinical findings of myelopathy underwent MRI (n= 59) on a 0.5 Tesla superconducting system. The other 41 patients underwent CT myelography. On MRI, herniation of a cervical soft disc was seen in 55 patients and the localisation corresponded well with the clinical symptoms. CT myelography showed a foraminal herniation in one of four selected patients with negative MRI. Fifty of 55 patients underwent ACD. All herniations were confirmed at operation, but in two patients there were important foraminal spurs not seen on MRI. It is concluded that $0.5 \mathrm{~T}$ MRI combined with plain radiographs offers an accurate, non-invasive test in the assessment of selected patients with cervical radiculopathy.
\end{abstract}

(F Neurol Neurosurg Psychiatry 1994;57:724-728)

Department of Neurosurgery, Universitair Ziekenhuis Antwerpen, Belgium E V de Kelft OLV Middelares Ziekenhuis Sint-Niklaas, Belgium $M$ van Vyve Correspondence to: Dr E Van de Kelft, Dienst Neurochirurgie, Universitair Ziekenhuis Antwerpen, Wilrijkstraat 10, B-2650 Edegem, Belgium.

Received 20 January 1993 and in revised form 26 July 1993. Accepted 21 October 1993

MRI with surface coils is currently the preferred method for evaluating degenerative cervical spine disease. In prospective and retrospective studies, MRI of the cervical spine has shown a high degree of correlation compared with myelography, CT, CT myelography, and surgical findings. ${ }^{1}$ The sensitivity of MRI is considered to be superior in evaluating disc degeneration and ligamenta flava hypertrophy. ${ }^{1-9}$ Biochemical disc degeneration, without structural degenerative changes, may be reflected by a low signal intensity in a cervical disc on T2-weighted MRI. ${ }^{9-11}$ Inadequate image contrast between bone and soft tissue may, however, diminish specificity of MRI. The differentiation between soft disc herniation and osteophytic spurs is not always obvious. MRI of the cervical spine associated with plain radiographs may be the best alternative in the preoperative neuroradiological assessement of patients suspected of a soft disc herniation with no major osteophytic spurs.

We prefer anterior cervical discectomy without interbody fusion (ACD) as the surgical procedure for patients with soft disc herniation, without clinical evidence of myelopathy and without advanced spondylosis, instability, or spurs. ${ }^{12-33}$ The ACD procedure is ideal to verify the exact location of disc herniations.

The purpose of this study was to describe the value of $M R I$ on a $0.5 \mathrm{~T}$ superconducting system associated with plain radiography of the cervical spine in selecting patients for ACD.

\section{Material and methods}

PATIENT SELECTION

During the period from June 1988 to June 1991 , a total of 100 patients with symptoms or signs of cervical radiculopathy, not subsiding after a period of conservative treatment, were referred for surgical treatment. Criteria of selection for ACD were: (a) no clinically manifest myelopathy and no prior cervical trauma or surgery; $(b)$ no signs of spondylosis, major osteophytes, or instability on plain radiographs (instability was defined as horizontal motion of a segment in excess of $3.5 \mathrm{~mm}$ or an angulation of one vertebral body of more than 11 degrees with respect to another); (c) one or more cervical soft disc herniations on MRI (figs $1 \mathrm{~A}$ and $1 \mathrm{~B}, 2,3$ )..$^{24}$

Plain radiographs were obtained in the lateral, anteroposterior, and $45^{\circ}$ oblique views. Flexion and extension radiographs were obtained for all patients to investigate instability.

\section{MRI EVALUATION}

After clinical and radiographical selection, 59 patients underwent surface coil MRI of the cervical spine. MRI was performed on a $0.5 \mathrm{~T}$ superconducting system (Siemens Magnetom). The MRI protocol included sagittal T1weighted (SE 30) images and sagittal gradient echo images (FLASH sequence GE 29 with $15^{\circ}$ flip angle). Additional axial $\mathrm{T} 1$-weighted images were obtained (SE 30 in the prone position and SE 40 with inclination) through the anatomical region of interest as defined by sagittal MRI, with $5 \mathrm{~mm}$ sections and disc 
Figure 1 (A) Midsagittal T1-weighted MRI image showing proved posterior soft disc herniation at C5C6 in a patient with $C 6$ radiculopathy to the right. Plain radiographs were normal. (B) Midsagittal T2-weighted MRI of the same patient showing important impression on the dural sac; this patient had no signs or symptoms of cervical myelopathy.
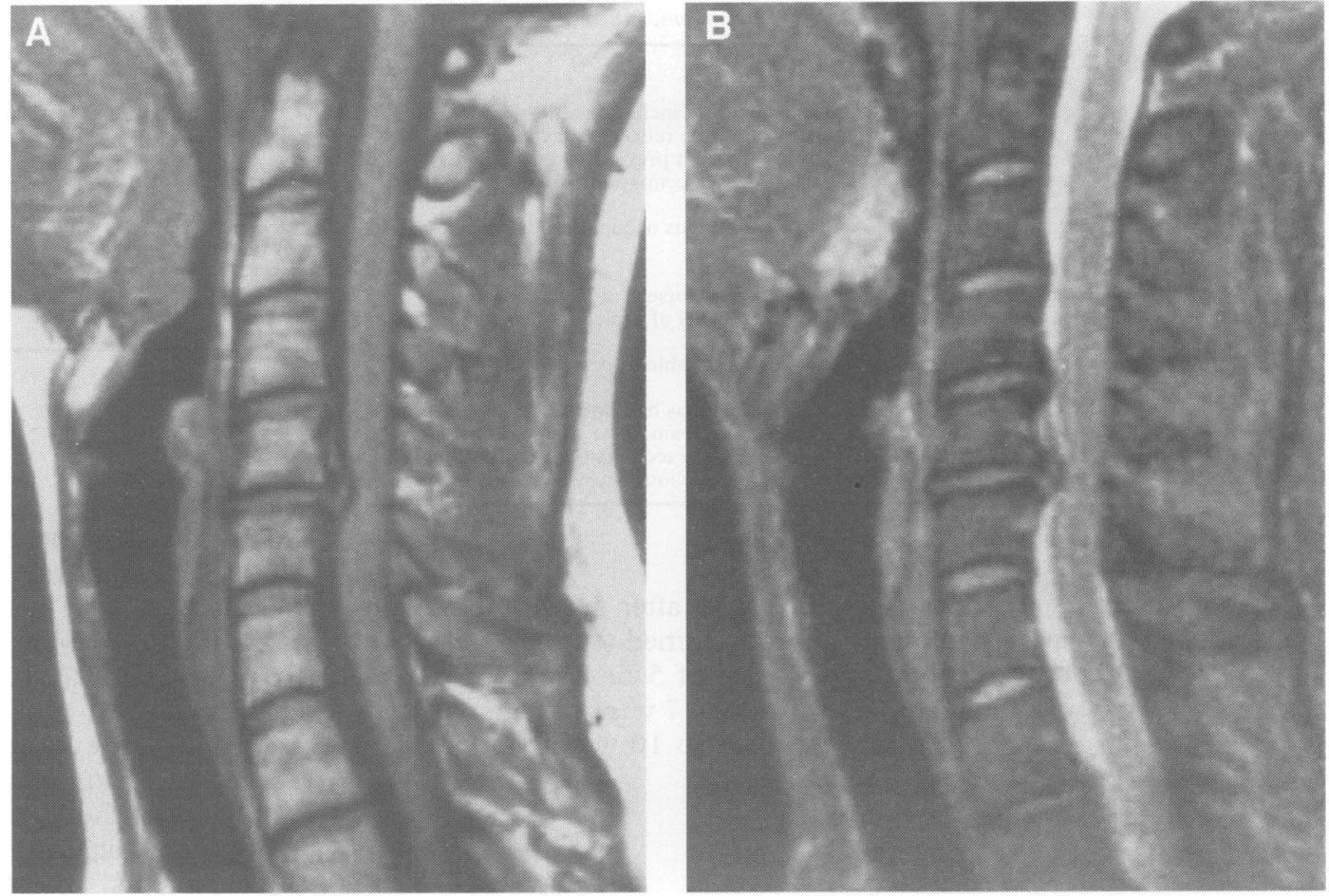

angled. The primary criterion for the interpretation of clinically significant lesions was the effacement of the subarachnoid space in the vicinity of the clinically affected nerve root on paraxial images.

\section{SURGICAL PROCEDURE}

Fifty ACD procedures were carried out on 50 patients within one month after MRI. There were 28 men and 22 women. The ages ranged from 29 to 54 (mean 36) years. All patients were operated on under general anaesthesia and with cervical traction. The anterior cervical spine was approached in the standard fashion from the left side. Fluoroscopy was used to locate the level and an operating microscope was employed routinely. The disc space was cleared of all disc material with abrasion of the adjacent vertebral end plates. The posterior part of the annulus fibrosus and minor posterior osteophytes ("transverse bar") were removed. The posterior third of the posterolateral ridge was routinely removed as the extruded disc fragment, if lateralised, is always found behind it. Finally, the posterior longitudinal ligament was excised to expose

Figure 2 Axial T1 weighted MRI of the same patient as in fig 1 showing effacement of the subarachnoid space at the right due to a soft disc herniation (arrow). the dural sac and the proximal part of the root sleeve. The foramina were explored routinely by a blunt hook. Minor osteophytes lateral to the uncinate process were removed with a fine angled curette. Patients did not wear cervical collars after surgery.

\section{OUTCOME ANALYSIS}

The outcome was measured by the functional-economic outcome rating scale described by Prolo et al (table 1), which consists of two subscales: the economic and the functional. ${ }^{25}$ This scale was initially developed for lumbar spine surgery, but may be applied for cervical radiculopathy as well, providing that no spinal cord symptoms are present. Outcome scores were assigned by the physician $(\mathrm{EVdeK})$ on the basis of clinical follow

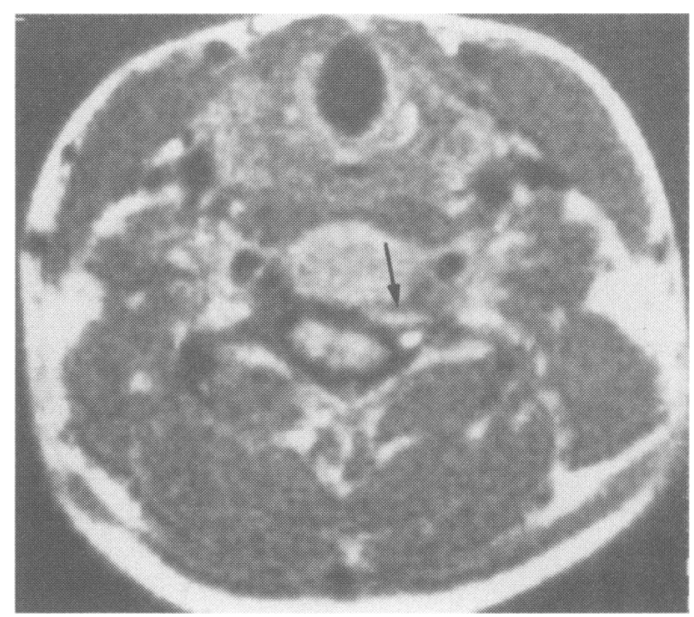

Figure 3 Axial T1-weighted MRI of a patient with a left-sided C7 radiculopathy due to a soft disc herniation C6-C7 on the left. Note the foraminal migration of the disc (arrow).

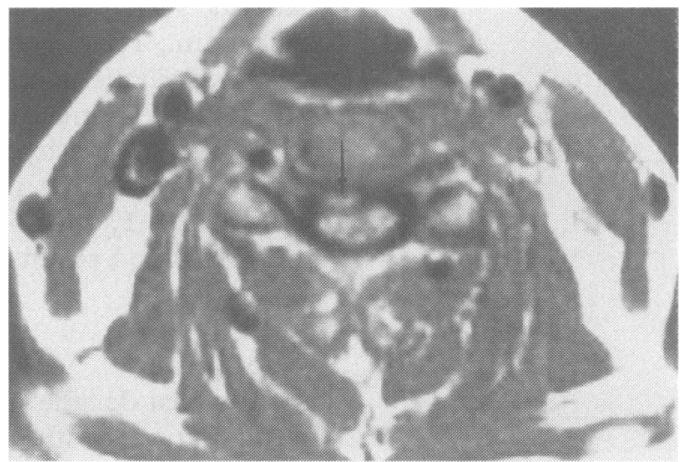


Table 1 Functional-economic outcome rating scale

Economic status:
E1 Complete invalid
E2 No gainful occupation including ability to do
housework or continue retirement activities
E3 Able to work but not at previous occupation
E4 Working at previous occupation part time or limited
status
E5 Able to work at previous occupation with no restriction
of any kind
Functional status:
F1 Total incapacity (or worse than before operation)
F2 Mild-to-moderate level of neck and/or irradiating arm
F3 Low level of pain and able to perform all activities
except sports
F4 No pain, but patient has had one or more recurrences
of neck or irradiating pain
F5 Complete recovery, no recurrent episodes of neck pain,
able to perform all previous sports activities

up at least one year after surgery. The subscale scores were summed to obtain an overall score. Total scores of 5 or less were considered poor; scores 6 to 7 were considered moderate; and scores 8 to 10 were considered to be good outcomes.

\section{Results}

CLINICAL FINDINGS

All patients complained of arm, shoulder, or neck pain and $85 \%$ had radicular pain in a dermatomal distribution. Fifty five per cent of patients had a sensory or reflex loss compatible with the location of the disc. Eighteen patients had clinical signs of myelopathy or they mentioned previous cervical trauma or surgery (fig 4).

\section{PLAIN RADIOGRAPHS}

Eighty two patients without myelopathy, previous neck surgery, or trauma as well as 18 patients with these clinical findings had plain radiographs taken of the cervical spine (fig 4) Twenty three were found to have spinal instability, spondylosis, or major osteophytic spurs.

Figure 4 Diagnostic imaging algorythm for cervical sofi disc herniation.
Table 2 Outcome of patients after operation as measured by the functional-economic outcome rating scale

\begin{tabular}{llc}
\hline Economic (\%) & Functional (\%) & Total (\%) \\
\hline E1 (0) & F1 (0) & $2(0)$ \\
E2 (2) & F2 (4) & $3(2)$ \\
E3 (8) & F3 (18) & $4(2)$ \\
E4 (32) & F4 (40) & $5(2)$ \\
E5 (58) & F5 (38) & $6(4)$ \\
& & $7(8)$ \\
& & $8(16)$ \\
& & $9(34)$ \\
& & $10(32)$ \\
\hline
\end{tabular}

\section{MRI EVALUATION}

MRI showed 56 herniated discs in 55 out of 59 selected patients. In four patients, MRI was normal. One patient had two herniated cervical discs. Twenty two discs were at $\mathrm{C} 5$ C6, 17 at $\mathrm{C} 6-\mathrm{C} 7,10$ at $\mathrm{C} 4-\mathrm{C} 5$, five at C3C4, and two at C7-T1. One herniation was medial, 27 were lateralised to the right, 28 to the left. In four patients, migration of disc fragments without rupture of the posterior longitudinal ligament was seen. In another three patients, migration of disc fragments with rupture of the posterior longitudinal ligament were found. All migrated disc fragments were lateralised; three to the left and four to the right.

In all patients, the presence of a cervical soft disc herniation was confirmed during the operation. In 47 of 50 operated cervical soft disc herniations, the operative findings correlated exactly with the preoperative MRI (94\%). All lateralised disc herniations were visualised when the posterolateral part of the uncinate process was removed. In one patient, we found rupture of the posterior longitudinal ligament, by contrast with the MRI findings. In two other patients we found an important lateral spur at the level of the herniation, compared with MRI on which it was interpreted as disc material. No major osteophytes were seen during the operation. CT myelography showed a lateral foraminal herniation in one of four selected patients with negative MRI.

OUTCOME AS MEASURED BY THE FUNCTIONAL ECONOMIC OUTCOME RATING SCALE

The mean economic outcome score of all patients was $4 \cdot 5$. The mean functional outcome score was $4 \cdot 1$ (table 2 ). Although all 50 patients initially noted symptomatic improvement postoperatively, two patients reported residual symptoms after a one year follow up with a functional outcome rate of F2. Four patients suffered temporary interscapular or neck pain. The overall satisfactory improvement was evident in $95 \%$ of this series after one year. No patient developed myelopathy or other radiculopathy. The total functionaleconomic outcome rating scale score of this series was $8 \cdot 1$, with $6 \%$ poor, $12 \%$ moderate, and $82 \%$ good results.

\section{Discussion}

For the past decade, the gold standard in evaluating patients with cervical radiculopathy has 
been CT myelography. ${ }^{26} 27$ Limitations exist, however, and are similar to those with plain CT. Moreover, CT myelography allows a limited view of the spine, usually covering only three to four cervical levels. The procedure is invasive and more costly as it requires a minimum stay of 24 hours in the hospital. MRI offers several advantages over CT myelography in screening for operable cervical spine lesions. ${ }^{1}$ MRI is able to survey the entire cervical spine without ionising radiation and is a non-invasive, outpatient examination, whereas CT myelography requires cervical or lumbar puncture and intrathecal contrast material, with the possibility of delayed adverse reactions. ${ }^{28}$ Furthermore, MRI provides useful information on pathology, allowing a non-invasive evaluation after surgical procedures and enabling a better understanding of surgical consequences. ${ }^{29}$

Several disadvantages have retarded the use of MRI as a screening method for degenerative disease of the cervical spine. These include the inability to obtain sections less than 3 to $5 \mathrm{~mm}$ thick (at least on our system), resulting in a partial volume averaging and suboptimal differentiation between osteophytes and disc material. Herniated discs extending into the obliquely oriented lateral root canals are not as reliably identified when spurs are prominent as on intrathecal contrast CT with $1.5 \mathrm{~mm}$ thick sections. Poor resolution between osteophytes, CSF, ligaments, and dura, all of which have similar low signal intensity, limits the specificity of MRI. GdDTPA enhanced T1-weighted images enhance soft tissue details in the neural foramina, allowing improved detection of foraminal encroachment. Gd-DTPA was not used in our patients as our goal was to establish a non-invasive screening sequence. As such, we prospectively analysed MRI in combination with plain films to exclude those patients with major osteophytes or spondylotic degeneration. We are well aware of the fact that selection of different optimal screening examinations for patients with radiculopathy is an option compromised by inexact correlation between clinical findings and anatomical lesions. Other series report $22 \cdot 7 \%$ of patients with cervical soft disc herniation presenting with myelopathy rather than radiculopathy. These patients were not selected for MRI in our study, but underwent CT myelography, most patients presenting with myelopathy have cervical spondylosis for which CT myelography seems to be more specific than MRI. ${ }^{1}$ Patients with bony canal stenosis often present with radiculopathy. These patients were assessed by CT myelography in our study. ${ }^{1}$

On sagittal or axial images, disc herniations are seen as focal protrusions of disc material behind the uncinate process, which may compress the thecal sac and spinal cord, often without myelopathy. The sequestered discs, seen in eight patients on MRI were all confirmed during surgery. The dislodgement of those disc fragments into the right or left half of the anterior epidural space and the high incidence of lateralised disc herniations, may be explained by a sagittally aligned collagen septum dividing the space between the posterior part of the disc and the posterior longitudinal ligament into two parts. ${ }^{30}$

Herniated disc material usually has a high signal intensity on T2-weighted images compared with the vertebral body and the spinal cord, both fat-containing structures with a low signal intensity on these MRI sequences (fig 1B). The intervertebral portion of the disc often degenerates, thereby producing lower signal intensity on T2-weighted images. Occasionally, the intervertebral portion of the disc has normal signal intensity, even though the disc is herniated. ${ }^{1}$ This was not found in our study. The T2-weighted pulse sequence is known to be poor in distinguishing between the ligamentous structures lining the spinal canal, and the dural sac. Therefore in some patients an apparent discrepancy exists between the $\mathrm{T} 2$-weighted gradient echo image which shows an anterior dural impression, and the T1-weighted section which does not (fig $1 \mathrm{~A}$ and $\mathrm{B}$ ).

MRI was able to detect at least one soft herniated disc in $91 \%$ of all selected patients. In one patient, the MRI was not able to disclose a disc herniation, that was shown later by CT-myelography.

In our opinion, clinically significant osteophytes adjoining herniated soft discs are unlikely to be missed by both combined plain film/MRI screening and the ACD procedure. Herniated discs and minor osteophytes in the lateral root canal are considered to be uncommon causes of cervical radiculopathy. ${ }^{31}{ }^{32}$ In our series, however, two patients had a disc herniated into the lateral foramen associated with a lateral spur. This was not seen on MRI because of the low specificity of $0.5 \mathrm{~T}$ MRI for foraminal structures. The specificity of MRI for cervical soft disc herniation, without spondylosis on plain films, is $96 \%$ in our study. This confirms the low specificity of MRI for foraminal lesions, which might occur more often than is generally accepted. ${ }^{32}$ The absence of fat in the cervical epidural space and its paucity in the neural foraminal canal limit the usefulness of T1-weighted sequences. Provided that sufficient MRI spatial resolution is available, T2-weighted sequences could be fruitful because signals from both the cerebrospinal fluid and flow in the intraspinal or canalicular venous plexus may highlight structures that posses a lesser T2-weighted signal, such as the spinal cord, nerve roots, and some adjacent normal or pathological bone and joints. Recently, Yousem et al introduced three dimensional Fourier transform (3DFT) MRI in assessing degenerative foraminal narrowing in the cervical canal with good results. ${ }^{32}$ Under these circumstances, MRI, even without the association of plain films, may become as specific as CT myelography in showing cervical root pathology. Osteophytes are preformed in cartilage, however, and evolve within several weeks to a few months. They may be of substantial size before ossification. ${ }^{33}$ In a recent study, these "cartilaginous caps", described 
during surgery, were not seen on CT myelography or on MRI. ${ }^{34}$ A cervical foraminal radiculopathy may exist, even without neuroradiological evidence.

In conclusion MRI with surface coils performed on a $0.5 \mathrm{~T}$ superconducting system combined with plain films of the cervical spine offers an accurate, non-invasive test for the preoperative evaluation of cervical radiculopathy without myelopathy. Lateral foraminal herniations may be missed, however, by classical 2 DFT imaging modalities. The proposed strategy: plain radiography plus MRI as a first screening for cervical radiculopathy should presently be the optimal procedure and by far the most cost effective. It may be the only imaging strategy required before appropriate treatment is applied.

1 Brown BM, Schwartz RH, Frank E, Blank NK. Preoperative evaluation of cervical radiculopathy and myelopathy by

2 Czervionke LF, Daniels DL. Cervical spine anatomy and pathologic process. Applications of new MR techniques. Rad Clin North Am 1988;26:921-47.

3 Enzmann DR, Rubin JB. Cervical spine: MR imaging with a partial flip angle, gradient-refocused pulse sequence. Part I. General considerations and disc disease. Radiology 1988;166:467-72.

4 Flannigan BD, Lufkin RB, McGlade C, et al. MR imaging of the cervical spine: neurovascular anatomy. $A \mathscr{f} N R$ 1987; 148:785-90.

5 Larsson EM, Holtas S, Croncvist S, Brandt L Comparison of myelography and magnetic resonance imaging in cervical spondylosis and disk herniation. Acta Radiol 1989;30:233-9.

6 Ross JS, Masaryk TJ, Modic MT. Postoperative cervical spine: MR assessment. $尹$ Comput Assist Tomogr 1987;11: 955-62.

7 Ross JS, Modic M, Masaryk TJ, Carter J, Marcus TE, Bohlman $\mathrm{H}$. Assessment of extradural degenerative disease with Gd-DTPA-enhanced MR imaging. Correlation with surgical and pathologic findings. AfNR 1989;10:1243-50.

8 Ross JS, Modic MT, Masaryk TJ. Tears of the annulus fibrosus: assessement with Gd-DTPA-enhanced MR imaging. AfNR 1989;10:1251-5.

9 Schiebler ML, Camerino VJ, Fallon MD, Zlatkin MB, Grenier N, Kressel H. In vivo and ex vivo magnetic resonance imaging evaluation of early disc degeneration with histopathologic correlation. Spine 1991;16:635-40.

10 Tertti M, Paajanen H, Laato M, Aho H, Komu M, Kormano $M$. Disc degeneration in magnetic resonance Kormano $M$. Disc degeneration in magnetic resonance imaging. A comparative biochemical, histologic, and
radiologic studies in cadaver species. Spine 1991;16: radiologic

11 Viikari-Juntura E, Raininko R, Videman Y, Porkka L Evaluation of cervical disc degeneration with ultralow field MRI and discography. An experimental study on cadavers. Spine 1989;14:616-9.

12 Bertalanffy H, Eggert HR. Complications of anterior cervical discectomy without fusion in 450 consecutive patients. Acta Neurochir (Wien) 1989;99:41-50.
13 Eriksen EF, Buhl M, Fode K, et al. Treatment of cervical disc disease using Cloward's technique. The prognostic value of clinical preoperative data in 1106 patients. Acta Neurochir (Wien) 1984;70:181-97.

14 Espersen JO, Buhl M, Eriksen EF, et al. Treatment of cervical disc disease using Cloward's technique. I General results, effect of different operative methods and complications in 1106 patients. Acta Neurochir (Wien) 1984;70:97-114.

15 Herkowitz HN, Kurz LT, Overholt DP. Surgical management of cervical soft disc herniation. A comparison between the anterior and posterior approach. Spine 1990;15:1026-30.

16 Edger MA, Nundy S. Innervation of the spinal dura mater. 千 Neurol Neurosurg Psychiatry 1964;29:530-4.

17 Robertson JT. Anterior cervical discectomy without fusion. In: Dunsker SB, ed. Cervical spondylosis. New York: Raven Press, 1981:181-1904

18 Robertson JT, Johnson SD. Anterior cervical discectomy without fusion: long-term results. Clin Neurosurg 1980 27:440-9.

19 Scoville WB. Types of cervical disc lesions and their surgical approaches. $\mathcal{F} A M A 1966 ; 196: 105-7$.

20 Simeone FA, Rothman RH. Cervical disc disease. In Rothman RH, Simeone FA, eds. The spine. Philadelphia: WB Saunders, 1982:491.

21 Wilson DH, Campbell DD. Anterior cervical discectomy without bone graft. $\mathcal{F}$ Neurosurg 1977;47:551-5.

22 Wohlert L, Buhl M, Eriksen EF, et al. Treatment of cervical disc disease using Cloward's technique. III Evaluation of cervical spondylotic myelopathy in 138 cases. Acta Neurochir (Wien) 1984;70:121-31.

23 Yamamoto I, Ikeda A, Shibuya N, Tsugane $R$, Sato $O$ Clinical long-term results of anterior discectomy without interbody fusion for cervical disc disease. Spine 1991 16:272-9.

24 Burrows E. The sagittal diameter of the spinal canal in cervical spondylosis. Clin Radiol 1963;14:77-86.

25 Husag L, Probst C. Microsurgical anterior approach to cervical discs. Review of 60 consecutive cases of discectomy without fusion. Acta Neurochir (Wien) 1984;73. 229-42.

25 Prolo DJ, Oklund SA, Butcher M. Toward uniformity in evaluating results of lumbar spine operations. A paradigm applied to posterior lumbar interbody fusions. Spine 1986;11:601-6.

26 Landman JA, Hoffman JC Jr, Braun IF, Barrow DL. Value of computed tomographic myelography in the recogniof computed tomographic myelography in the reco
tion of cervical herniated disc. AfNR 1984;5:391-5.

27 Sobel DF, Barkovich AJ, Munderloh SH. Metrizamide myelography and postmyelographic computed tomography: comparative adequacy in the cervical spine. $A \mathscr{f} N R$ 1984;5:385-90

28 Van de Kelft E, Bosmans J, Van Vyve M, Parizel PM, Selosse P. Intracerebral hemorrhage after iohexol myelography. Report of a case and review of the literature. Neurosurgery 1991;28:570-4

29 Van de Kelft E, Van Vyve M, Selosse P. Postsurgical follow-up by MRI of anterior cervical discectomy without fusion. Eur $\mathcal{F}$ Radiol 1992;15:196-9.

30 Schellinger D, Manz HJ, Vidic B, et al. Disk fragment migration. Radiology 1990;175:831-6.

31 Tsuruda JS, Norman D, Dillon W, Newton TH, Mills DG. Three-dimensional gradient-recalled MR imaging as a screening tool for the diagnosis of cervical radiculoas a screening tool for the diagnd $A 7 R$ 1990;154:375-83.

32 Youssem DM, Atlas SW, Goldberg HI, Grossman RI Degenerative narrowing of the cervical spine neural Degenerative narrowing of the cervical spine neural
foramina: evaluation with high-resolution $3 \mathrm{DFT}$ foramina: evaluation with high-resolution 3DF

33 Sabiston CP, Adams ME, Li DKB. Magnetic resonance imaging of osteoarthritis: correlation with gross pathology using an experimental model. $\mathcal{F}$ Orthop Res 1987;5: 164-72.

34 Houser OW, Onofrio BM, Miller GM, Folger WN, Smith PL, Kallman DA. Cervical neural foraminal stenosis: computerized tomographic myelography diagnosis. f Neurosurg 1993;79:84-8. 